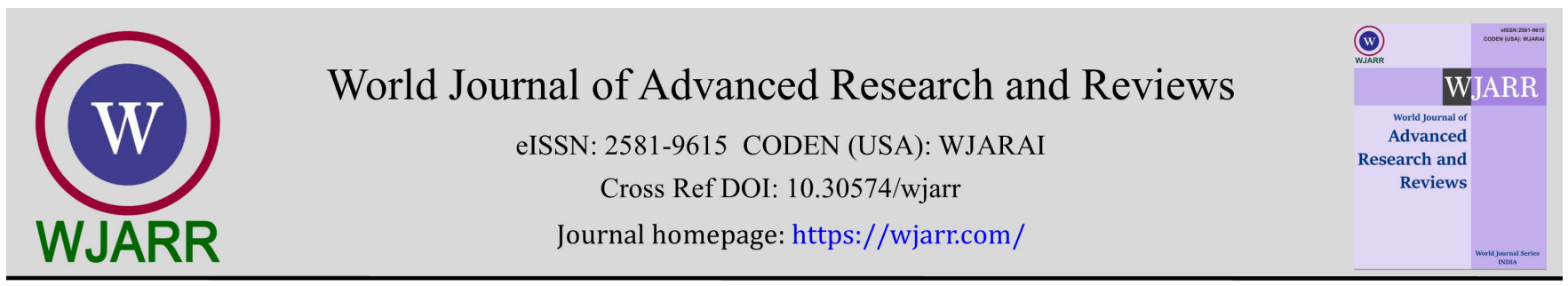

(RESEARCH ARTICLE)

\title{
Occupational effect of spray painting fumes on some biochemical parameters in automobile spray painters in Yenagoa Bayelsa State, Nigeria
}

\author{
Emmanuel Tonbra Egoro $1{ }^{*}$, Emmanuel Sunday Oni ${ }^{2}$ and Jonathan Ebipade Lawrence 1 \\ ${ }^{1}$ Department of Medical Laboratory Science, Faculty of Basic Medical Sciences, Niger Delta University, P.M.B. 071, \\ Wilberforce Island, Bayelsa State, Nigeria. \\ ${ }^{2}$ Department of Medical Laboratory Science, Faculty of Sciences, Rivers State University, Port-Harcourt, Rivers State, \\ Nigeria.
}

World Journal of Advanced Research and Reviews, 2021, 09(02), 038-044

Publication history: Received on 13 January 2021; revised on 01 Februay 2021; accepted on 03 Februay 2021

Article DOI: https://doi.org/10.30574/wjarr.2021.9.2.0033

\begin{abstract}
Automobile spray painters are often prone to chemical toxicity due to their routine work. This study was aimed at the occupational effect of spray painting fumes on some biochemical parameters in automobile spray painters. Five milliliters of blood specimen were collected into lithium heparin anti-coagulated bottles from twenty five automobile spray painters with $\leq 10$ years working experience (experimental group one), $\geq 11$ years working experience (experimental group two) and non-automobile spray painters which were monitored as control group respectively. After this, plasma alanine aminotransferase, aspartate aminotransferase, C-reactive protein, urea and creatinine were measured quantitatively using a spectrophotometer. The mean values of all the measured biochemical parameters showed no statistically significant differences $(\mathrm{p}>0.05)$ in the automobile spray painters with $\leq 10$ years working experience as compared with that of the control group with the exception of plasma C-reactive protein, while those with $\geq 11$ years working experience showed statistically significant differences $(\mathrm{p}<0.05)$ in plasma alanine aminotransferase, aspartate aminotransferase and C-reactive protein however, the plasma urea and creatinine showed no statistically significant differences ( $p>0.05)$. In conclusion, the concentration of plasma alanine aminotransferase, aspartate aminotransferase and C-reactive protein may be altered in automobile spray painters with $\geq 11$ years working experience, thus these biochemical parameters should be monitored regularly in spray painters within this category of working experience
\end{abstract}

Keywords: Occupational effect of spray painting fumes; Biochemical parameters; Automobile spray painters; Yenagoa; Bayelsa State; Nigeria

\section{Introduction}

Spray painting is a technique employed in painting where a device sprays a coating through the air onto a surface. Automobile spray painters are professionals that are prone to chemical toxicity due to their routine work which exposes them to health and environmental risks such as dust, air pollutants and various toxic chemicals while working in the garage [1]. Occupationally non-exposed individuals are found to have low toxic chemicals such as lead, cadmium, chromium, zinc and copper in their blood compared with occupationally exposed individuals such as automobile spray painters, automobile mechanics etc [2].

Occupational exposure to these toxic chemicals could pose serious health challenges which are mainly associated with gout, renal failure, encephalopathy and hepatotoxicity [3]. The liver being the principal organ of xenobiotics metabolism

${ }^{*}$ Corresponding author: Emmanuel Tonbra Egoro

Department of Medical Laboratory Science, Faculty of Basic Medical Sciences, Niger Delta University, P.M.B. 071, Wilberforce Island, Bayelsa State, Nigeria.

Copyright (C) 2021 Author(s) retain the copyright of this article. This article is published under the terms of the Creative Commons Attribution Liscense 4.0. 
is often exposed to agents that may be considered as toxic [4]. Exposure to toxic products of volatile hydrocarbons, benzene and petroleum fumes affect both liver and kidney [5] while exposure to dust and other air pollutants have been reported to be associated with cardiovascular disease [6].

About 100 different organic compounds were identified in a recent analysis of indoor air in an auto painting facility with $90 \%$ being xylene, acetone, methyl isobutyl ketone, toluene, methyl ethyl ketone and hexane [7]. Various combinations of these solvents which are hazardous when inhaled are used along with other additives (retarders, accelerators and levelers) to reduce the viscosity of the material to a spray-able consistency [8]. Some adverse effects associated with exposure to these organic compounds in oil based paints and coatings by construction and maintenance painters include increased rates of throat, lungs and larynx cancer, leukemia, impaired nervous system function, liver disease, kidney disease and birth defects among offspring [9]

Automobile spray painters are known to be frequently exposed to toxic chemicals and solvents from spray paint components. Taking into consideration that liver is the primary organ for the detoxification of toxins while the kidneys are responsible for metabolic wastes removal, it is vital to carry out this study which is aimed at the occupational effect of spray painting fumes on some biochemical parameters such as aspartate aminotransferase, alanine aminotransferase (liver enzymes), C-reactive protein (inflammatory biomarker), urea and creatinine (renal biomarkers) since availability of data on these biochemical parameters are rare.

\section{Material and methods}

\subsection{Study area}

This study was carried out in the Department of Medical Laboratory Science, Faculty of Basic Medical Science, College of Health Sciences, Niger Delta University, Wilberforce Island, Bayelsa State, Nigeria.

\subsection{Volunteer group}

Seventy five apparently healthy male volunteers categorized into three groups as shown were randomly recruited for this study.

\subsection{Control group}

This group consisted of twenty five apparently healthy male volunteers within the age range of 35-45 years who by virtue of their profession are white collar jobs workers.

\subsection{Experimental group one}

This group consisted of twenty five apparently healthy male volunteers who are automobile spray painters with $\leq 10$ years working experience and are within the age range of 35-45 years.

\subsection{Experimental group two}

This group consisted of twenty five apparently healthy male volunteers who are automobile spray painters with $\geq 11$ years working experience and are within the age range of 35-45 years.

As at the time of carrying out this study all the recruited volunteers in both the control and experimental groups were free from any ailments and were also not addicted to cigarette smoking, snuffing and drugs abuse, thus ruling out the likely effects of these lifestyle variables on the obtained results.

\subsection{Sample collection}

Five milliliters of blood specimens were withdrawn from each of the apparently healthy recruited volunteers (control and experimental groups) via a vein-puncture technique and dispensed into lithium heparin anti-coagulated bottles respectively. The blood specimen in each bottle was mixed carefully in order to ensure homogenicity and prevention of blood coagulation and there after spun for ten minutes at 1,500 revolution/minute using Gulfex Medical and Scientific macro centrifuge model 800D England. The obtained plasma was subsequently used for the quantitative measurement of the following biochemical parameters: aspartate aminotransferase, alanine aminotransferase, C-reactive protein,, urea and creatinine. The manufacturers' standard operational procedures were strictly adhered to while performing these tests. 


\subsection{Equipment}

Medifield equipment and scientific Limited Vis-spectrophotometer with model number S23A13192 was used for the absorbance measurement of the respective biochemical parameters. Other equipment that were used included Medifield equipment and scientific Limited incubator with model number DNP-9052A as well as Gulfex medical scientific Limited macro-centrifuge with model number 800D.

\subsection{Measurement of alanine aminotransferase}

Alanine aminotransferase was measured in accordance with the colorimetric method as reported earlier by [10] using reagents manufactured by Randox Laboratories, Limited, 55, Diamond Road, Crumlin, County, Antrim, BT294QY, United Kingdom.

\subsection{Measurement of aspartate aminotransferase}

Aspartate aminotranferase was measured in accordance with the colorimetric method as reported earlier by [10] using reagents manufactured by Randox Laboratories, Limited, 55, Diamond Road, Crumlin, County, Antrim, BT294QY, United Kingdom.

\subsection{Measurement of C-reactive protein}

C-reactive protein was measured in accordance with the latex turbidimetry method as reported earlier by [11] using reagents manufactured by Spin-React Diagnostics, Spain.

\subsection{Measurement of urea}

Urea was measured in accordance with the Urease-Berthelot method as reported earlier by [11] using reagents manufactured by Randox Laboratories, Limited, 55, Diamond Road, Crumlin, County, Antrim, BT294QY, United Kingdom.

\subsection{Measurement of creatinine}

Creatinine was measured in accordance with the Jaffe reaction method as reported earlier by [11] using reagents manufactured by Randox Laboratories, Limited, 55, Diamond Road, Crumlin, County, Antrim, BT294QY, United Kingdom.

\subsection{Statistical analysis}

The data obtained from the apparently healthy recruited spray painters (experimental groups) and control group via questionnaire were analyzed using descriptive statistic of frequency and percentage while the results obtained from the quantitative measurement of their plasma biochemical parameters were expressed as mean and standard deviation with the differences between the groups compared using the student' $t$ ' tests. A $p$-value of $p<0.05$ was considered statistically significant.

\section{Results and discussion}

Automobile spray painters are professionals that are prone to health and environmental risks every day due to their occupational activities which regularly expose them to air pollution, dust and various toxic chemicals as compared to the general population. The harmful effects of these automobile spray paints coupled with the gross noncompliance with safety measures by majority of spray painters within the studied community have become a burden that demands swift attention. In furtherance to increase knowledge on these harmful effects, data on compliance with safety measures during the course of work were obtained from the recruited volunteers in experimental groups one and two via questionnaire as shown in Table-1and Table-2 respectively.

The data as shown in Table- 1 revealed that $100 \%$ of the volunteers with $\leq 10$ years working experience (experimental group one) are compliant with the use of leather gloves as a safety measure, $68 \%$ are compliant with the use of nose mask as a safety measure while $32 \%$ are noncompliant, $100 \%$ are noncompliant with the use of long-sleeve jacket as a safety measure, $40 \%$ are compliant with the use of goggle as a safety measure while the remaining $60 \%$ are noncompliant and $100 \%$ are noncompliant with the use of faceplate as a safety measure. These findings as established in this study and further illustrated with a Bar chart as shown in Figure-1 are assumed to be contributory to the easy passage of paint fumes into the body system of these spray painters which in turn may influence the danger on their health. 
Table 1 Compliance with safety measures by experimental group one volunteers with $\leq 10$ years working experience

\begin{tabular}{|l|l|l|l|}
\hline \multicolumn{1}{|c|}{ Variables } & \multicolumn{1}{|c|}{ Response } & Frequency (n=25) & \multicolumn{1}{|c|}{ Percentage } \\
\hline Use of leather gloves & Yes & 25 & $100 \%$ \\
& No & Nil & $0 \%$ \\
\hline Use of nose mask & Yes & 17 & $68 \%$ \\
& No & 8 & $32 \%$ \\
\hline Use of long-sleeve jacket & Yes & Nil & $0 \%$ \\
& No & 25 & $100 \%$ \\
\hline Use of goggle & Yes & 10 & $40 \%$ \\
& No & 15 & $60 \%$ \\
\hline Use of faceplate & Yes & Nil & $0 \%$ \\
& No & 25 & $100 \%$ \\
\hline
\end{tabular}

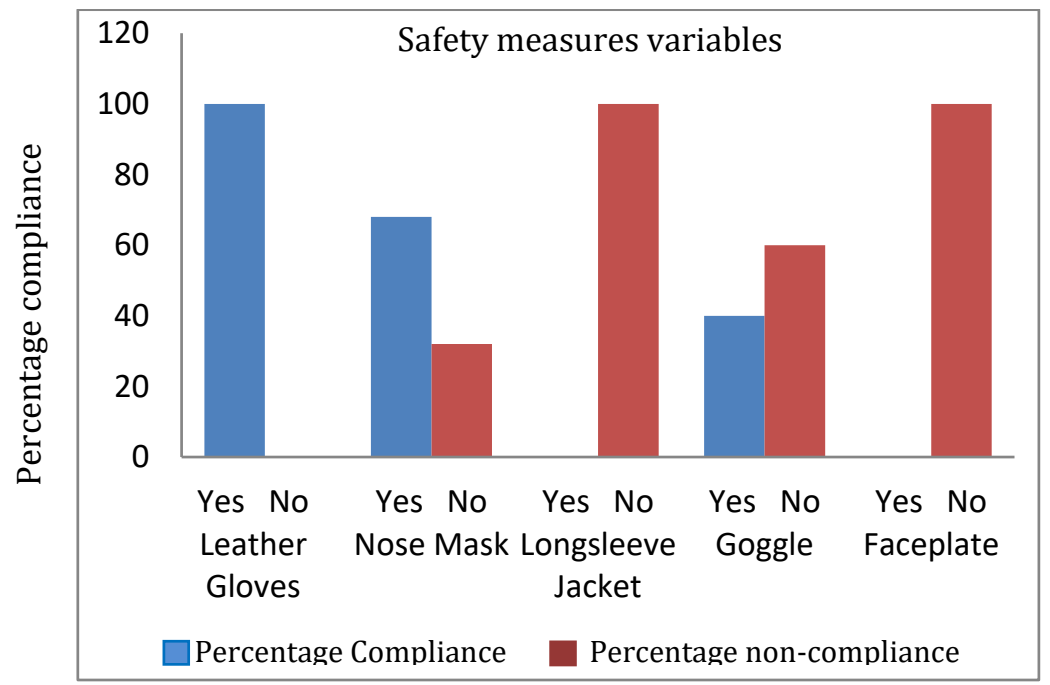

Figure 1 A Bar chart showing the percentage compliance and noncompliance with safety measures by spray painters with $\leq 10$ years working experience (experimental group one)

The data in Table- 2 revealed that $100 \%, 20 \%$ and $40 \%$ of the volunteers with $\geq 11$ years working experience (experimental group two) are compliant with the use of leather gloves, nose mask and goggle respectively while $80 \%$, $100 \%, 60 \%$ and $100 \%$ are noncompliant with the use of nose mask, long-sleeve jacket, goggle and faceplate respectively as safety measures. These findings particularly as regards the gross neglect of nose mask as established in this study and further illustrated with a Bar chart as shown in Figure-2 may expose the spray painters to easy passage of paint fumes into their body system via inhalation during the course of work which may in turn put them at the risks of hepatotoxicity since the liver is the primary organ that is responsible for the detoxification of toxic substances in humans.

Table 2 Compliance with safety measures by experimental group two volunteers with $\geq 11$ years working experience

\begin{tabular}{|l|l|l|l|}
\hline \multicolumn{1}{|c|}{ Variables } & \multicolumn{1}{|c|}{ Response } & Frequency (n=25) & \multicolumn{1}{|c|}{ Percentage } \\
\hline Use of leather gloves & Yes & 25 & $100 \%$ \\
& No & Nil & $0 \%$ \\
\hline Use of nose mask & Yes & 5 & $20 \%$ \\
& No & 20 & $80 \%$ \\
\hline Use of long-sleeve jacket & Yes & Nil & $0 \%$ \\
& No & 25 & $100 \%$ \\
\hline Use of goggle & Yes & 10 & $40 \%$ \\
& No & 15 & $60 \%$ \\
\hline Use of faceplate & Yes & Nil & $0 \%$ \\
& No & 25 & $100 \%$ \\
\hline
\end{tabular}




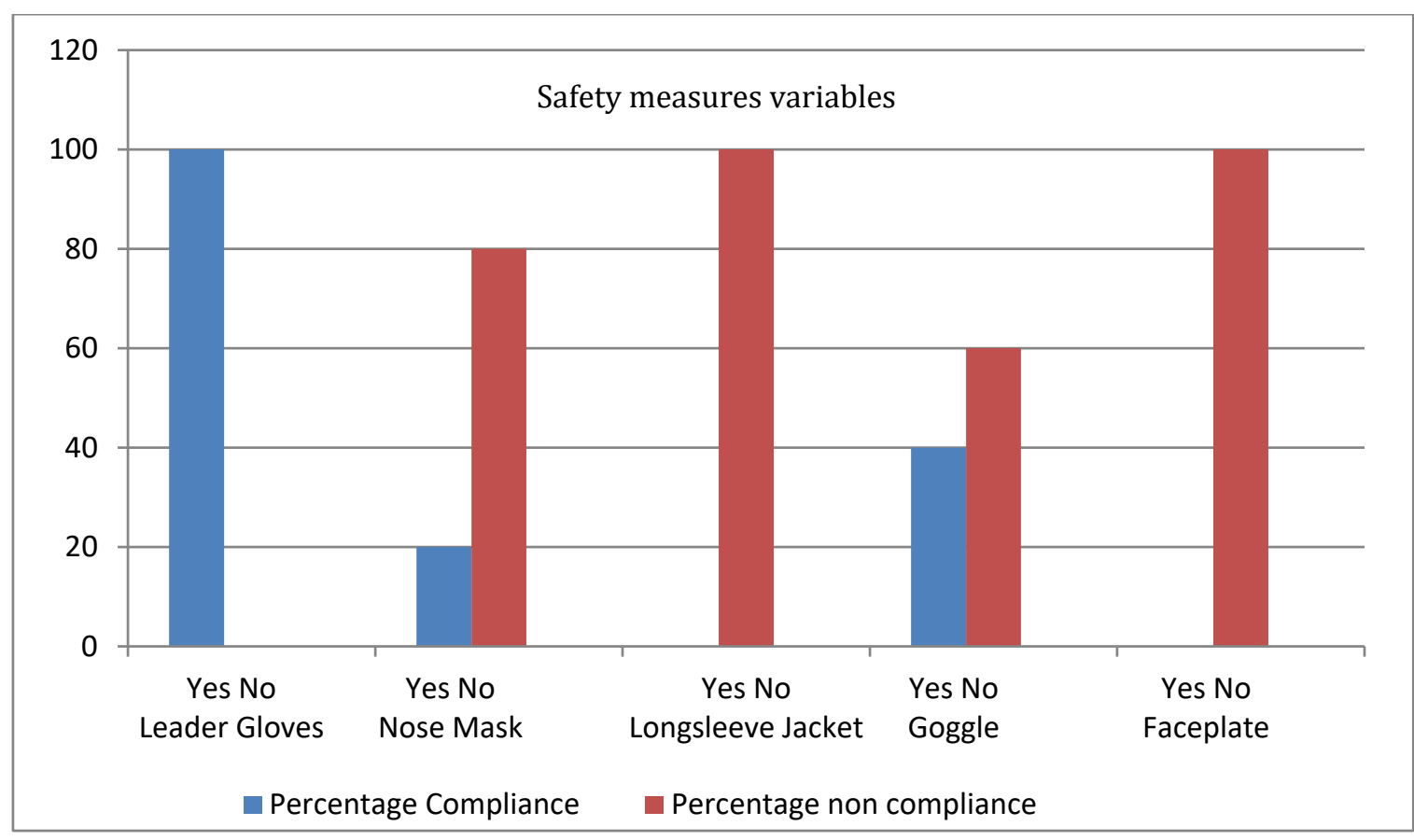

Figure $2 \mathrm{~A}$ Bar chart showing the percentage compliance and noncompliance with safety measures by spray painters with $\geq 11$ years working experience (experimental group two)

In this study comparison was also made between the mean values of plasma aspartate aminotransferase, alanine aminotransferase, C-reactive protein, urea and creatinine in automobile spray painters with $\leq 10$ years (experimental group one) and $\geq 11$ years (experimental group two) working experience respectively with that of non-automobile spray painters (control group). The results of automobile spray painters with $\leq 10$ years working experience (experimental group one) as shown in Table-3 revealed no statistically significant difference ( $>0.05$ ) in all the measured plasma biochemical parameters as compared with that of the control group respectively exception being plasma C-reactive protein that showed statistically significant difference $(\mathrm{p}<0.05)$ as compared with that of the control group. This finding which is established in this study is suggestive that exposure to automobile spray paint for a duration of $\leq 10$ years may pose inflammatory disorder on the health status of automobile spray painters.

Table 3 The plasma values of biochemical parameters measured in control group compared to the experimental group one volunteers with $\leq 10$ years working experience.

\begin{tabular}{|l|l|l|l|l|}
\hline Parameters & Control group $(\mathbf{n = 2 5})$ & Experimental group $(\mathbf{n = 2 5})$ & p-value & \multicolumn{1}{|c|}{ Remark } \\
\hline ALT $(\mathrm{U} / \mathrm{I})$ & $9.48 \pm 1.02$ & $9.50 \pm 1.03$ & $\mathrm{P}>0.05$ & NS \\
\hline AST $(\mathrm{U} / \mathrm{I})$ & $7.71 \pm 0.92$ & $7.74 \pm 0.95$ & $\mathrm{P}>0.05$ & $\mathrm{NS}$ \\
\hline CRP $(\mathrm{mg} / \mathrm{L})$ & $3.11 \pm 0.18$ & $13.15 \pm 1.98$ & $\mathrm{P}<0.05$ & $\mathrm{~S}$ \\
\hline Urea $(\mathrm{mmol} / \mathrm{L})$ & $9.70 \pm 1.07$ & $9.72 \pm 1.08$ & $\mathrm{P}>0.05$ & NS \\
\hline Crea $(\mu \mathrm{mol} / \mathrm{L})$ & $85.10 \pm 0.91$ & $85.30 \pm 0.94$ & $\mathrm{P}>0.05$ & NS \\
\hline
\end{tabular}

KEYS: Values are in mean \pm S.D., ALT $=$ Alanine aminotransferase, AST $=$ Aspartate aminotransferase, $\mathrm{CRP}=\mathrm{C}$-reactive protein, Crea $=$ creatinine, $\mathrm{NS}=$ Not statistically significant, $S=$ statistically significant, $n=$ Number of volunteers

However the results of automobile spray painters with $\geq 11$ years working experience (experimental group two) as shown in Table-4 revealed statistically significant differences $(\mathrm{p}<0.05)$ in plasma alanine aminotransferase, plasma aspartate aminotransferase and plasma C-reactive protein as compared with that of the control group respectively, while plasma urea and plasma creatinine showed no statistically significant differences ( $p>0.05)$ as compared with that of the control group respectively. The finding as established in this study is suggestive that exposure to automobile spray paint for a duration of $\geq 11$ years may pose hepatic disorder which is presumed to be associated with exposure and inhalation of some toxic chemicals and solvents found in spray paint that are presumed to have led to liver injury and subsequently triggered the leakage and release of these enzymes from the liver to the blood. Another finding as 
established in this study is the significant elevation of C-reactive protein $(\mathrm{p}<0.05)$ which is suggestive that exposure to automobile spray paint for a duration of $\geq 11$ years may pose inflammatory disorder that is probably associated with the inhalation of toxic chemical substances and solvents present in the spray paint which in turn had led to systemic inflammation with the resultant release of interleukin 6 and other cytokines that are capable of triggering the synthesis and elevation of $\mathrm{C}$-reactive protein in the blood of the Automobile spray painters

Table 4 The plasma values of biochemical parameters measured in control group compared to the experimental group two volunteers with $\geq 11$ years working experience

\begin{tabular}{|l|l|l|l|l|}
\hline Parameters & Control group $(\mathbf{n = 2 5})$ & Experimental group $(\mathbf{n = 2 5})$ & p-value & \multicolumn{1}{|c|}{ Remark } \\
\hline ALT(U/I) & $9.48 \pm 1.02$ & $20.12 \pm 2.11$ & $\mathrm{P}<0.05$ & $\mathrm{~S}$ \\
\hline AST $(\mathrm{U} / \mathrm{I})$ & $7.71 \pm 0.92$ & $19.02 \pm 1.98$ & $\mathrm{P}<0.05$ & $\mathrm{~S}$ \\
\hline CRP $(\mathrm{mg} / \mathrm{L})$ & $3.11 \pm 0.18$ & $17.98 \pm 2.20$ & $\mathrm{P}<0.05$ & $\mathrm{~S}$ \\
\hline Urea $(\mathrm{mmol} / \mathrm{L})$ & $9.70 \pm 1.07$ & $9.69 \pm 1.06$ & $\mathrm{P}>0.05$ & $\mathrm{NS}$ \\
\hline Crea $(\mu \mathrm{mol} / \mathrm{L})$ & $85.10 \pm 0.91$ & $85.15 \pm 0.93$ & $\mathrm{P}>0.05$ & $\mathrm{NS}$ \\
\hline
\end{tabular}

KEYS: Values are in mean \pm S.D., ALT $=$ Alanine aminotransferase, AST $=$ Aspartate aminotransferase, $\mathrm{CRP}=\mathrm{C}$-reactive protein, $\mathrm{Crea}=\mathrm{creatinine}, \mathrm{NS}=$ Not statistically significant, $\mathrm{S}=$ statistically significant, $\mathrm{n}=$ Number of volunteers

\section{Conclusion}

In conclusion this study has established that exposure and inhalation of fumes generated from automobile spray paint for duration of $\geq 11$ years may induce hepato-inflammatory disorders in automobile spray painters, while exposure and inhalation of fumes generated from automobile spray paint for duration of $\leq 10$ years may induce inflammatory disorder only in automobile spray painters.

\subsection{Recommendations}

From the findings of this study, it is recommended that

- The use of safety gadgets such as nose mask, long sleeve jacket, goggle and faceplate should be adhered to strictly by automobile spray painters during the course of work so as to reduce the risk of inhaling the toxic chemicals and solvents found in automobile spray paints

- Automobile spray painters with $\geq 11$ years working experience should go for periodic hepato-inflammatory check-up with the aim to quickly reverse the concentrations of these hepato-inflammatory biochemical parameters to normal if found elevated

\section{Compliance with ethical standards}

\section{Acknowledgments}

The leaders of the spray painters union Bayelsa State branch and all the volunteers are acknowledged with thanks

\section{Disclosure of conflict of interest}

All authors have no conflict of interest.

\section{Statement of ethical approval}

This study was carried strictly in compliance with the principle of Helsinki declaration of 1975 as revised in 2008 . Verbal informed consent was also obtained from all the recruited volunteers who were made to know the reason for which their blood specimens were being collected. Ethical approval was obtained from the ethical committee of Niger Delta University, Wilberforce Island, Bayelsa State, Nigeria as well as leaders of the automobile spray painters union.

\section{Author's contribution}

Emmanuel Tonbra Egoro was responsible for initiating the research, thus coming up with the title, aim of the research, materials and methods including the experimental design, analysis of the plasma biochemical parameters withdrawn 
from the volunteers and designing the tables and figures format. Emmanuel Sunday Oni was responsible for the statistical analysis, results and discussion as well as referencing of the authors on the reference list. Jonathan Ebipade Lawrence was responsible for seeking verbal informed consent and approval from the volunteersused for this research work as well as collection of their respective blood specimens. He was also responsible for the formulation of the questionnaire from which the volunteers" data were obtained.

\section{Statement of informed consent}

Informed consent was obtained from all individual participants included in the study.

\section{References}

[1] Kamal A, Malik RN, Fatima N. Chemical exposure in occupational settings and related health risks: a neglected area of research in Pakistan. Environmental toxicology and pharmacology. 2012; 34(1): 46-58.

[2] Ayiward LL, Kirman CR,Schoeeny R. Evaluation of bio-monitoring data from the CDC National Exposure Report in a risk assessment context: perspectives across chemicals. Environmental health perspective. 2012;121(3): 287-294.

[3] Herman DS, Geraldine M, Venkatesh T. Evaluation, diagnosis and treatment of lead poisoning in a patient with occupational lead exposure: a case presentation. Journal of occupational medical toxicology. 2007; 2: 6-7.

[4] Ajani EO, Ajibola A, Salau BA. Preliminary report on hepatic and cardiovascular risk assessment of automobile mechanics in Nigeria. African journal of biotechnology. 2011; 10(9): 1705-1711.

[5] Soni K, Sharma RK, Gupta A. Impact of petroleum fumes on liver and kidney functioning of petrol filling attendants and garage attendants working in South Haryana, India. European journal of pharmacology medicine and research. 2016; 3(8): 569-573.

[6] Simkhovich BZ, Kleinman MT, Kloner RA. Air pollution and cardiovascular injury. Journal of america cardiology. 2008; 52(9): 719-726.

[7] Daniell W, Stebbins A,Kalman D, O’Donnell JF, Horstman SW. The contributions to solvents uptake by skin and inhalation exposure. America industrial.hygiene association journal. 1992; 53(2): 124-129.

[8] Selikoff IJ. Investigations of health hazards in the painting trades. National institute of science total environment. 1975; 29(1): 28-37.

[9] International Agency for Research on Cancer (IARC), World Health Organization. Monographs on the evaluation of carcinogenic risks to humans: some organic solvents, resin monomers and related compounds, pigments and occupational exposures in paints manufacturing and painting. IARC. 1989; 47: 329-344.

[10] Ifenkwe JC, Nwanjo HU, Nwosu DC, Solomon EA, Bot YS. Heavy metals bioaccumulation and lipid peroxidation damage in residents of a gas flaring community. International journal of advances in scientific research and engineering. 2018; 4(7): 140-150.

[11] Egoro ET, Oni ES, Chukwuma SA. Studies on selected biochemical and hormonal profile status in plasma of some roadside welders in Ajegunle, Nigeria. Global journal of medical research. 2019; 19(6): 17-23. 